\title{
TERCEIRO TEMPO: ANÁLISE DO DESEMPENHO FINANCEIRO DOS MAIORES CLUBES DESPORTIVOS MUNDIAIS E APLICAÇÃO DAS TÉCNICAS DE ÍNDICE PADRÃO E MODELO DE SOLVẾNCIA
}

\author{
Renato Cruz Mendes \\ Doutorando em Ciências Contábeis - UFRJ \\ Instituto Federal de Educação, Ciência e Tecnologia do Rio de Janeiro - IFRJ \\ renato.mendes@ifrj.edu.br \\ Rafael Simão Gonçalves \\ Mestre em Ciências Contábeis - UFRJ \\ Instituto Federal de Educação, Ciência e Tecnologia do Rio de Janeiro - IFRJ \\ rafael.goncalves@ifrj.edu.br
}

\section{Resumo}

Objetivo: Analisar o desempenho econômico-financeiro dos clubes de futebol com as vinte maiores receitas do mundo e aplicar as técnicas de análise das demonstrações contábeis de índice padrão e modelo de solvência.

Método: De forma descritiva, com uma abordagem quantitativa e, do ponto de vista dos procedimentos técnicos, como uma pesquisa bibliográfica e documental, aplicou-se os indicadores de liquidez, endividamento e rentabilidade às demonstrações contábeis dos vinte clube com as maiores receitas mundiais. Para a construção do índice-padrão, distribuiu-se os indicadores na classe de percentis decis, demonstrando o resultado e interpretação para cada clube.

Originalidade/Relevância: A relevância da pesquisa encontra-se pautada na necessidade de alinhar o desempenho esportivo ao financeiro, valorizando uma gestão responsável, transparente e profissional que utiliza de técnicas e estratégias de gestão na captação, aplicação e administração dos recursos financeiros, além de servir de parâmetro para avaliação do desempenho de demais entidades desportivas. Resultados: De forma geral, destaca-se que os clubes apresentaram níveis de liquidez abaixo do recomendado pela literatura acadêmica, financiamento de suas atividades, majoritariamente, com capital de terceiros e proporção de dívidas maior a curto prazo. Quanto à rentabilidade, mesmo sendo clubes com grande captação de receitas, apenas uma pequena parte desta transformou-se em lucro, demonstrando uma grande estrutura de custos e despesas.

Contribuições teóricas: Com base nas lacunas identificadas, esta pesquisa contribui para a evidenciação da importância de uma gestão profissional nos clubes desportivos, salientando que o desempenho financeiro correlaciona-se com os resultados alcançados esportivamente

Palavras-chave: Indicadores financeiros. Índice-padrão. clubes desportivos.

\section{$\underline{\text { Cite como }}$}

American Psychological Association (APA)

Mendes, R. C., \& Gonçalves, R. S. Terceiro tempo: análise do desempenho financeiro dos maiores clubes desportivos mundiais e aplicação das técnicas de índice padrão e modelo de solvência. PODIUM Sport, Leisure and Tourism Review, São Paulo, 10(4), 1-21. https://doi.org/10.5585/podium.v10i4.17006. 
Mendes, R. C., \& Gonçalves, R. S. Terceiro tempo: análise do desempenho financeiro dos maiores clubes desportivos mundiais e aplicação das técnicas de índice padrão e modelo de solvência

\title{
THIRD HALF: ANALYSIS OF THE FINANCIAL PERFORMANCE OF THE LARGEST SPORTS CLUBS IN THE WORLD AND APPLICATION OF STANDARD INDEX TECHNIQUES AND SOLVENCY MODEL
}

\begin{abstract}
Objective: Analyze the economic and financial performance of football clubs with the twenty largest revenues in the world and apply the analysis techniques of the financial statements of standard index and solvency model.

Method: In a descriptive manner, with a quantitative approach and, from the point of view of technical procedures, such as a bibliographic and documentary research, the liquidity, indebtedness and profitability indicators were applied to the financial statements of the twenty clubs with the highest worldwide revenues. For the construction of the standard index, the indicators were distributed in the percentile percentile class, showing the result and interpretation for each club.

Originality / Relevance: The relevance of the research is based on the need to align sporting and financial performance, valuing responsible, transparent and professional management that uses management techniques and strategies in the capture, application and administration of financial resources, in addition to serve as a parameter for evaluating the performance of other sports entities.

Results: In general, it is noteworthy that the clubs presented liquidity levels below that recommended by the academic literature, financing of their activities, mostly, with third party capital and a higher proportion of debts in the short term. Regarding profitability, even though they are clubs with a large revenue collection, only a small part of this turned into profit, demonstrating a large structure of costs and expenses.

Theoretical contributions: Based on the identified gaps, this research contributes to highlight the importance of professional management in sports clubs, emphasizing that financial performance is correlated with the results achieved in sports.
\end{abstract}

Keywords: Financial indicators. Standard index. sports clubs.

\section{TERCER TIEMPO: ANÁLISIS DEL DESEMPEÑO FINANCIERO DE LOS CLUBES DEPORTIVOS MÁS GRANDES DEL MUNDO Y APLICACIÓN DE TÉCNICAS DE ÍNDICES ESTÁNDAR Y MODELO DE SOLVÊNCIA}

\section{Resumen}

Objetivo: Analizar el desempeño económico y financiero de los clubes de fútbol con los veinte mayores ingresos del mundo y aplicar las técnicas de análisis de los estados financieros de índice estándar y modelo de solvência.

Método: Descriptivamente, con un enfoque cuantitativo y, desde el punto de vista de los procedimientos técnicos, como una investigación bibliográfica y documental, los indicadores de liquidez, endeudamiento y rentabilidad se aplicaron a los estados financieros de los veinte clubes con los mayores ingresos mundiales. Para la construcción del índice estándar, los indicadores se distribuyeron en la clase de percentil percentil, mostrando el resultado y la interpretación para cada club.

Originalidad / Relevancia: La relevancia de la investigación se basa en la necesidad de alinear el desempeño deportivo y financiero, valorando la gestión responsable, transparente y profesional que utiliza técnicas y estrategias de gestión en la captura, aplicación y administración de recursos financieros, además de Servir de parámetro para evaluar el rendimiento de otras entidades deportivas.

Resultados: En general, cabe destacar que los clubes presentaron niveles de liquidez inferiores a los recomendados por la literatura académica, financiando sus actividades, principalmente, con capital de terceros y una mayor proporción de deudas a corto plazo. En cuanto a la rentabilidad, a pesar de que son clubes con una gran recaudación de ingresos, solo una pequeña parte de esto se convirtió en ganancias, lo que demuestra una gran estructura de costos y gastos.

Contribuciones teóricas: con base en las brechas identificadas, esta investigación contribuye a resaltar la importancia de la gestión profesional en los clubes deportivos, enfatizando que el rendimiento financiero está correlacionado con los resultados logrados en los deportes.

Palabras clave: Indicadores financeiros. índice estândar. clubes deportivos. 
Braga, D. C., Paixão, C. V., Pereira, I. B., \& Santos, M. P. (2021, set./dez.). Fatores de competitividade que influenciam a escolha do turista entre o transporte aéreo e os trens de alta velocidade: uma revisão da literatura publicada em inglês (1995-2020)

\section{Introdução}

Os clubes desportivos tornaram-se uma das principais opções de lazer selecionada pela sociedade no que refere-se à prática de desportos, convívio social e promoção de grandes espetáculos. Dentre as diversas modalidades, o futebol destaca-se como a principal, chamando a atenção de milhões de pessoas ao redor do mundo e influenciando a esfera econômica (Vargas, 1995; Holanda et al, 2012).

Apesar de sua natureza ser caracterizada pela conquista das competições disputadas, o passar dos anos transformou sua atividade em um grande negócio, com uma movimentação monetária bilionária, despertando assim o interesse de grandes investidores, que passaram a implantar uma gestão profissional com o intuito de conectar o desempenho financeiro ao esportivo (Barros, Assaf \& Earp, 2010; Sakin, Acikalin \& Soyguden, 2017).

Mesmo com um movimento caminhando para uma gestão profissionalizada, estudos como os de Soares (2007) e Marques (2014) evidenciaram alguns problemas recorrentes das entidades desportivas, como a ocupação de cargos de gerência por questões políticas e de amizade com a diretoria, insolvência provocada pelo endividamento excessivo e até envolvimento judiciais causado por práticas ilegais.

Desse modo, tal evolução fez com que a atuação dos clubes desportivos passasse a ser bem parecida com a das empresas com fins lucrativos, caracterizada pela utilização e implementação de estratégias e técnicas de gestão que possibilitem a manutenção de sua competitividade, o fortalecimento da captação de investimentos e a melhora em sua situação econômica e financeira (Tachizawa, Ferreira \& Fortuna, 2004; Dos Santos et al, 2020).

Assim, as causas do sucesso ou fracasso de um clube estão intrinsecamente ligadas ao modo como agem dentro e fora do campo e à forma como são gerenciados. Um clube mais eficiente na captação, aplicação e gestão dos recursos financeiros possuirá uma maior capacidade de investimento e, consequentemente, um melhor desempenho desportivo.

Diante dos cenários desportivos e financeiros citados acima, este artigo tem por objetivo analisar o desempenho econômico-financeiro dos clubes de futebol com as vinte maiores receitas do mundo e aplicar as técnicas de análise das demonstrações contábeis de índice padrão e modelo de solvência. Ressalta-se ainda que a apreciação dos indicadores possibilita uma visão mais apurada sobre a saúde financeira dos clubes, apontando seus pontos fortes e fracos, a necessidade de um planejamento mais estratégico e de uma tomada de decisão mais eficiente no que se refere ao orçamento e estrutura de capital. 
Mendes, R. C., \& Gonçalves, R. S. Terceiro tempo: análise do desempenho financeiro dos maiores clubes desportivos mundiais e aplicação das técnicas de índice padrão e modelo de solvência

\section{Referencial Teórico}

\section{Indicadores financeiros}

Em um ambiente de negócios altamente competitivo, com grandes investimentos e inovações, acrescidos ainda do aumento contínuo de exigência de eficiência operacional, é cada vez maior a demanda de uma análise a fim de controlar e mensurar a situação econômicofinanceira das diversas organizações.

Segundo Padoveze e Benedicto (2014, p. 3), a análise financeira consiste em um "processo meditativo sobre os números de uma entidade, para avaliação de sua situação econômica, financeira, operacional e de rentabilidade".

Nesse sentido, a compreensão do desempenho empresarial e sua análise dá-se por meio de três pontos fundamentais: Liquidez (Situação Financeira), Rentabilidade (Situação Econômica) e Endividamento (Estrutura de Capital) (Marion, 2017).

Assim, esta análise surge com a finalidade de oferecer aos diversos e múltiplos usuários da informação um real diagnóstico do desempenho organizacional, beneficiando, por exemplo, desde bancos e/ou instituições financeiras que desejam verificar a capacidade de pagamento de seus clientes, entidades governamentais que pretendem mensurar o crescimento econômico de uma região, até investidores que busquem observar a rentabilidade de seus negócios.

Em prosseguimento, para uma eficaz análise econômico-financeira das organizações e evidenciando seu tripé fundamental citado anteriormente, utilizam-se dos denominados indicadores, que consistem em relações estabelecidas entre duas grandezas, auxiliando os analistas na interpretação da performance organizacional.

Nesta pesquisa, foram utilizados os principais indicadores de liquidez, endividamento e rentabilidade, conforme demonstra a tabela abaixo: 
Braga, D. C., Paixão, C. V., Pereira, I. B., \& Santos, M. P. (2021, set./dez.). Fatores de competitividade que influenciam a escolha do turista entre o transporte aéreo e os trens de alta velocidade: uma revisão da literatura publicada em inglês $(\mathbf{1 9 9 5 - 2 0 2 0})$

\section{Tabela 1}

Indicadores Financeiros

\begin{tabular}{|c|c|c|}
\hline INDICADOR: & FÓRMULA: & INTERPRETAÇÃO: \\
\hline Liquidez & disponibilidades & Demonstra quanto a empresa possui de ativo \\
\hline Imediata & $P C$ & disponível para quitar suas obrigações de curto prazo. \\
\hline Liquidez & $A C$ & Demonstra quanto a empresa possui de bens e \\
\hline Corrente & $\overline{P C}$ & direitos para quitar suas obrigações de curto prazo. \\
\hline \multirow{2}{*}{ Liquidez Geral } & $A C+$ Real.a $L P$ & \multirow{2}{*}{$\begin{array}{l}\text { Demonstra quanto a empresa possui de bens e } \\
\text { direitos para quitar o total de suas obrigações. }\end{array}$} \\
\hline & $P C+P \tilde{\mathrm{n}} C$ & \\
\hline \multirow{2}{*}{$\begin{array}{l}\text { Participação de } \\
\text { Capital de Terceiros }\end{array}$} & Passivo Exigível & \multirow{2}{*}{$\begin{array}{l}\text { Demonstra a participação de capital de } \\
\text { terceiros na estrutura de capital da empresa. }\end{array}$} \\
\hline & Passivo $+P L$ & \\
\hline \multirow{2}{*}{$\begin{array}{l}\text { Composição } \\
\text { do Endividamento }\end{array}$} & $P C$ & \multirow{2}{*}{$\begin{array}{l}\text { Demonstra a proporção das obrigações de } \\
\text { curto prazo em relação às obrigações totais. }\end{array}$} \\
\hline & $\overline{\text { Passivo Exigível }}$ & \\
\hline \multirow{2}{*}{$\begin{array}{l}\text { Margem } \\
\text { Líquida }\end{array}$} & $L L$ & \multirow{2}{*}{$\begin{array}{l}\text { Demonstra quanto a empresa obteve de lucro } \\
\text { líquido em relação ao faturamento obtido. }\end{array}$} \\
\hline & $\overline{\text { Receita }}$ & \\
\hline \multirow{2}{*}{ ROI } & $L L$ & \multirow{2}{*}{$\begin{array}{l}\text { Demonstra quanto a empresa obteve de } \\
\text { retorno sobre o total investido. }\end{array}$} \\
\hline & $\overline{\text { Ativo }}$ & \\
\hline \multirow{2}{*}{ ROE } & $L L$ & \multirow{2}{*}{$\begin{array}{l}\text { Demonstra quanto a empresa obteve de } \\
\text { retorno sobre o capital próprio. }\end{array}$} \\
\hline & $\overline{P L}$ & \\
\hline
\end{tabular}

Fonte: Elaborado pelos autores.

Diante dos motivos expostos acima, a análise por meio de indicadores econômicofinanceiros despertou interesse por parte de teóricos e acadêmicos com aplicação em diversos segmentos e ramos de atuação. Fanti et al (2016) buscaram identificar e avaliar as políticas de gestão da companhia Vale com a aplicação dos mesmos. Seus resultados evidenciaram que a transparência da empresa proporcionou segurança e confiabilidade na gestão situação do momento. Em outro sentido, a pesquisa de Lemos e Soares (2012) utilizou os indicadores para construir um modelo de previsão de insolvência para micro e pequenas empresas, tendo o estudo alcançado um grau de predição acima de $95 \%$.

Contextualizando com a temática deste estudo, é possível encontrar na literatura acadêmica algumas pesquisas dentro do segmento dos clubes desportivos e do futebol. Ferreira, Marques e Macedo (2018) mostraram a relação entre os desempenhos esportivos e financeiros dos clubes de futebol participantes da série A e B entre os períodos de 2013 e 2016, apontando uma relação positiva e significante de receita bruta, despesa com salários e endividamento com o desempenho esportivo dos clubes. Já Gonçalves et al (2020), examinaram a relação entre o desempenho esportivo e econômico-financeiro com base nas fontes de receitas dos clubes desportivos brasileiros. Os resultados encontrados evidenciaram que o desempenho esportivo afeta positiva e significantemente o desempenho econômico-financeiro dos clubes, sendo a 
Mendes, R. C., \& Gonçalves, R. S. Terceiro tempo: análise do desempenho financeiro dos maiores clubes desportivos mundiais e aplicação das técnicas de índice padrão e modelo de solvência

receita com venda de jogadores a variável mais explicada pelo desempenho esportivo do ano anterior.

\section{Índice-padrão}

Levando em consideração as especificidades de cada segmento da atuação empresarial, o resultado de um mesmo indicador pode ser considerado satisfatório para uma empresa e ruim para outra. Isto ocorre porque a estrutura patrimonial das empresas varia de acordo com sua ocupação.

Assim, para uma eficiente análise do desempenho empresarial é de extrema relevância a aplicação de uma base que funcione como uma legenda para efeitos de comparações.

Em decorrência desta demanda define-se o principal objetivo do índice-padrão, que pode ser definido como um referencial de comparação, que indica se a empresa em análise enquadra-se no padrão para o setor ou possui desempenho mais ou menos satisfatórios. Em outras palavras, o processo de comparação com os padrões visa à identificação do desempenho empresarial em relação ao ramo de atuação ou setor pertencente (Silva, 2017; Padoveze \& Benedicto, 2014).

Nesse sentido, estudos foram realizados objetivando construir um referencial de comparação para diversos segmentos de atuação, como por exemplo, o de Silva et al (2015), que estruturou uma base para o setor empresarial de exploração de rodovias e o de Duarte e Lamounier (2007), para o setor de construção civil.

Dentro do segmento esportivo, a técnica do índice padrão já foi aplicada na pesquisa de Jahara, Mello \& Afonso (2016), tendo como público alvo as equipes brasileiras que participaram da série A no ano de 2014, apontando, em geral, baixo desempenho financeiro para os indicadores de liquidez, endividamento, rentabilidade e solvência.

\section{Procedimentos metodológicos}

Este trabalho define-se, dentro dos níveis de pesquisa, como um estudo descritivo pois "visa descrever as características de determinada população, ou o estabelecimento de relações entre variáveis" (Kauark, Manhães e Medeiros, 2010, p. 28). Com uma abordagem quantitativa, define-se, do ponto de vista dos procedimentos técnicos, como uma pesquisa bibliográfica e documental (Gil, 2008). 
Com base em estudos que se propuseram a compreender a situação financeira das empresas atuantes em setores importantes da economia, este trabalho objetivou analisar o desempenho econômico e financeiro das vinte equipes de futebol que obtiveram as maiores receitas no cenário econômico mundial, segundo o Football Money League 2019, publicado pela Deloitte, classificando-as conforme a aplicação da técnica de índice padrão.

Assim, os clubes desportivos selecionados foram, respectivamente, Real Madrid CF, FC Barcelona, Manchester United FC, FC Bayern Munich, Manchester City FC, Paris SaintGermain FC, Liverpool FC, Chelsea FC, Arsenal FC, Tottenham Hotspur FC, Juventus FC, Borussia Dortmund, Club Atlético de Madrid, FC Internazionale, AS Roma, Schalke 04, Everton FC, AC Milan, Newcastle United FC e West Ham United FC.

Para alcançar tal objetivo, aplicaram-se os indicadores financeiros apresentados no referencial teórico às demonstrações contábeis publicadas pelas equipes público-alvo para o ano de 2017/2018.

Para a construção do Índice-padrão utilizou-se a metodologia proposta por Matarazzo (1998) e Marion (2017). Inicialmente, selecionou-se entidades de um mesmo setor (clubes desportivos) e com estruturas semelhantes (maiores faturamentos mundiais). Em seguida, distribuiu-se os indicadores na classe de percentis decis, que conforme expõe Padoveze \& Benedicto (2014, p. 230), "são os valores que dividem a série estatística em dez partes iguais".

A Figura 01 abaixo, demonstra a posição dos indicadores financeiros em ordem crescente dispostos na curva de distribuição normal e em seu respectivo decil.

\section{Figura 01}

\section{Curva de Distribuição Normal dos Decis}

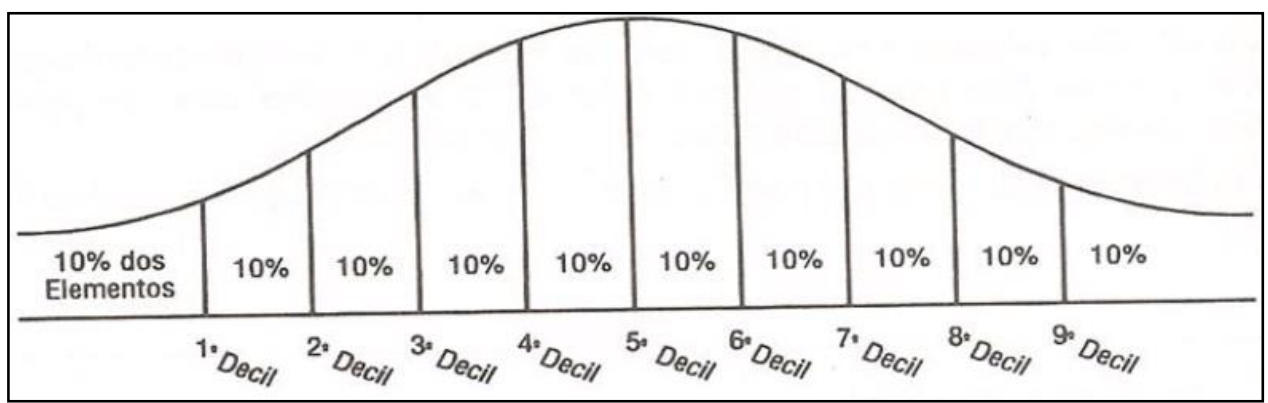

Fonte: Elaborados pelos autores.

Para a classificação dos indicadores financeiros, utilizou-se a tabela abaixo, proposta por Matarazzo (1998) e adaptada pelos autores, onde a posição dos mesmos definiram sua 
Mendes, R. C., \& Gonçalves, R. S. Terceiro tempo: análise do desempenho financeiro dos maiores clubes desportivos mundiais e aplicação das técnicas de índice padrão e modelo de solvência

situação, a saber: péssimo, muito ruim, ruim, razoável, bom, muito bom e ótimo, de acordo com a dinâmica exigida de cada indicador. Além disso, o ranking elaborado levou em consideração o somatório dos pontos obtidos por cada indicador de acordo com sua posição nos percentis.

\section{Tabela 2}

Conceito e Pontuação dos Indicadores Segundo os Decis

\begin{tabular}{|c|c|c|c|c|c|c|c|c|c|c|c|}
\hline \multicolumn{12}{|c|}{ Indicadores quanto maior, melhor } \\
\hline Indicadores & 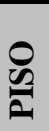 & $\begin{array}{c}1^{\circ} \\
\text { Decil }\end{array}$ & $\begin{array}{c}2^{\circ} \\
\text { Decil }\end{array}$ & $\begin{array}{c}3^{\circ} \\
\text { Decil }\end{array}$ & $\begin{array}{c}4^{0} \\
\text { Decil }\end{array}$ & $\begin{array}{c}5^{\circ} \\
\text { Decil }\end{array}$ & $\begin{array}{c}6^{0} \\
\text { Decil }\end{array}$ & $\begin{array}{c}7^{\circ} \\
\text { Decil }\end{array}$ & $\begin{array}{c}\mathbf{8}^{\circ} \\
\text { Decil }\end{array}$ & $\begin{array}{c}9^{\circ} \\
\text { Decil }\end{array}$ & 을 \\
\hline Liq. Imediata & \multirow{6}{*}{\multicolumn{2}{|c|}{ 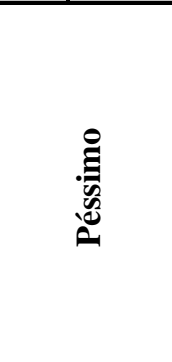 }} & \multirow{6}{*}{ 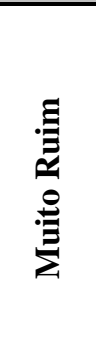 } & \multirow{6}{*}{\multicolumn{2}{|c|}{ 龍 }} & \multirow{6}{*}{ 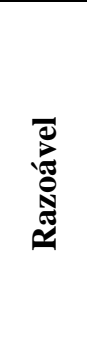 } & \multirow{6}{*}{\multicolumn{2}{|c|}{ ڤี }} & \multirow{6}{*}{ 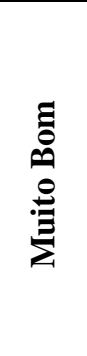 } & \multirow{6}{*}{\multicolumn{2}{|c|}{ (ְ. }} \\
\hline Liq. Corrente & & & & & & & & & & & \\
\hline Liq. Geral & & & & & & & & & & & \\
\hline Mar. Líquida & & & & & & & & & & & \\
\hline ROI & & & & & & & & & & & \\
\hline ROE & & & & & & & & & & & \\
\hline PONTOS & 0 & 1 & 2 & 3 & 4 & 5 & 6 & 7 & 8 & 9 & 10 \\
\hline \multicolumn{12}{|c|}{ Indicadores quanto menor, melhor } \\
\hline Indicadores & $\begin{array}{l}0 \\
\mathscr{2} \\
2\end{array}$ & $\begin{array}{c}1^{\circ} \\
\text { Deci }\end{array}$ & $\begin{array}{c}2^{\mathbf{0}} \\
\text { Decil }\end{array}$ & $\begin{array}{c}3^{\circ} \\
\text { Decil }\end{array}$ & $\begin{array}{c}4^{\circ} \\
\text { Decil }\end{array}$ & $\begin{array}{c}5^{\circ} \\
\text { Decil }\end{array}$ & $\begin{array}{c}6^{\mathbf{0}} \\
\text { Decil }\end{array}$ & $\begin{array}{c}7^{\circ} \\
\text { Decil }\end{array}$ & $\begin{array}{c}\mathbf{8}^{\mathbf{0}} \\
\text { Decil }\end{array}$ & $\begin{array}{c}9^{\circ} \\
\text { Decil }\end{array}$ & $\stackrel{0}{\underline{x}}$ \\
\hline $\begin{array}{l}\text { Part. Capital } \\
\text { de Terceiros }\end{array}$ & \multirow{2}{*}{\multicolumn{2}{|c|}{ : }} & \multirow{2}{*}{ 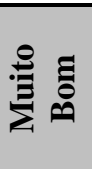 } & \multirow{2}{*}{\multicolumn{2}{|c|}{ ఐే }} & \multirow{2}{*}{ 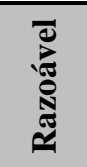 } & \multirow{2}{*}{\multicolumn{2}{|c|}{ 脑 }} & \multirow{2}{*}{ 总 } & \multirow{2}{*}{\multicolumn{2}{|c|}{ 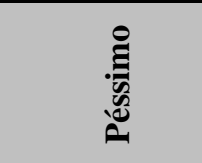 }} \\
\hline $\begin{array}{l}\text { Composição } \\
\text { de Endivid. }\end{array}$ & & & & & & & & & & & \\
\hline PONTOS & 10 & 9 & 8 & 7 & 6 & 5 & 4 & 3 & 2 & 1 & 0 \\
\hline
\end{tabular}

Fonte: Matarazzo (1998), adaptado pelos autores.

Os indicadores de Liquidez Imediata, Corrente e Geral, Margem Líquida, ROI e ROE possuem a dinâmica de quanto maior, melhor, ou seja, quanto maior for o resultado destes indicadores mais favorável e eficiente é a situação da empresa. Em contrapartida, os indicadores de endividamento (composição do endividamento e participação de capital de terceiros) possuem a dinâmica de quanto menor, melhor, que reflete que quanto menor for o valor do indicador, melhor a situação das entidades.

Por fim, com a finalidade de analisar a solvência dos clubes estudados, foram aplicados nas demonstrações contábeis os diversos modelos preditivos construídos ao longo dos anos por autores e estudiosos da temática, conforme expõe a tabela a seguir: 
Braga, D. C., Paixão, C. V., Pereira, I. B., \& Santos, M. P. (2021, set./dez.). Fatores de competitividade que influenciam a escolha do turista entre o transporte aéreo e os trens de alta velocidade: uma revisão da literatura publicada em inglês $(\mathbf{1 9 9 5 - 2 0 2 0})$

\section{Tabela 3}

Modelos de Solvência

\begin{tabular}{|c|c|c|}
\hline AUTORES & MODELOS & INTERPRETAÇÃO \\
\hline $\begin{array}{l}\text { Altman } \\
\text { (1968) }\end{array}$ & $\begin{array}{c}\mathrm{Z} 2=-1,84-0,51 \mathrm{X} 1+6,32 \mathrm{X} 3+0,71 \mathrm{X} 4 \\
+0,53 \mathrm{X} 5 \\
\text { Onde, } \\
\mathrm{Z}=\text { total ou escore de pontos obtidos } \\
\mathrm{X} 1=\text { Ativo Circulante-Passivo Circulante/ } \\
\text { Ativo Total } \\
\text { X3 = LAJIR/Ativo Total } \\
\text { X4 = Patrimônio Líquido/Exigível Total } \\
\text { X5 = Vendas / Ativo Total }\end{array}$ & $\begin{array}{l}\mathrm{Z}>0=\text { Solvente } \\
\mathrm{Z}<0=\text { Insolvente }\end{array}$ \\
\hline $\begin{array}{l}\text { Elizabetsky } \\
\text { (1976) }\end{array}$ & $\begin{array}{c}\mathrm{Z}=1,93 \mathrm{X} 1-0,20 \mathrm{X} 2+1,02 \mathrm{X} 3+1,33 \mathrm{X} 4 \\
-1,12 \mathrm{X} 5 \\
\text { Onde } \\
\mathrm{Z}=\text { total ou escore de pontos obtidos } \\
\mathrm{X} 1 \text { = Lucro Líquido / Vendas } \\
\mathrm{X} 2=\text { Disponível / Ativo Permanente } \\
\mathrm{X} 3=\text { Contas a Receber / Ativo Total } \\
\text { X4 = Estoque / Ativo Total } \\
\text { X5 = Passivo Circulante / Ativo Total }\end{array}$ & $\begin{array}{l}\mathrm{Z}>0,5=\text { Solvente } \\
\mathrm{Z}<0,5=\text { Insolvente }\end{array}$ \\
\hline $\begin{array}{l}\text { Kanitz } \\
(1978)\end{array}$ & $\begin{array}{c}\mathrm{FI}=0,05 \mathrm{X} 1+1,65 \mathrm{X} 2+3,55 \mathrm{X} 3-1,06 \mathrm{X} 4 \\
-0,33 \mathrm{X} 5 \\
\text { Onde }, \\
\mathrm{FI}=\text { fator de insolvência } \\
\mathrm{X} 1=\text { lucro líquido/patrimônio líquido } \\
\mathrm{X} 2=(\text { ativo circulante }+ \text { realizável a longo } \\
\text { prazo }) / \text { exigível total } \\
\mathrm{X} 3=(\text { ativo circulante }- \text { estoques }) / \text { passivo } \\
\text { circulante } \\
\mathrm{X} 4=\text { ativo circulante/passivo circulante } \\
\text { X5 = exigível total/patrimônio líquido }\end{array}$ & $\begin{array}{c}\text { FI }<-3=\text { Insolvente } \\
\text { FI }>-3 \text { e }<0=\text { Indefinida } \\
\text { FI }>0=\text { Solvente }\end{array}$ \\
\hline
\end{tabular}

Fonte: Elaborados pelos autores.

\section{Resultados e discussões}

Antes de iniciar os resultados e discussões obtidos neste estudo, é de suma importância demonstrar a origem dessas que são as maiores receitas de clubes de futebol do mundo. Há uma série de métricas, financeiras e não financeiras, que podem ser usadas para comparar clubes, incluindo comparecimento, número de torcedores, audiência de transmissão e sucesso em campo. Em seu estudo, a Deloitte (2019) avalia os clubes na geração de receita a partir do estádio (Matchday), direitos de transmissão de televisão (Broadcasting) e marketing (Commercial), e os classifica nessa base. Cabe ressaltar que o mercado futebolístico, em nível mundial, apresentou receitas no valor de $€ 8.3 \mathrm{bn}$ com os vinte maiores clubes, sendo $17 \%$ em Matchday, 43\% em Broadcasting e 40\% em Commercial. 
Mendes, R. C., \& Gonçalves, R. S. Terceiro tempo: análise do desempenho financeiro dos maiores clubes desportivos mundiais e aplicação das técnicas de índice padrão e modelo de solvência

\section{Gráfico 1}

Origem das Receitas dos Clubes

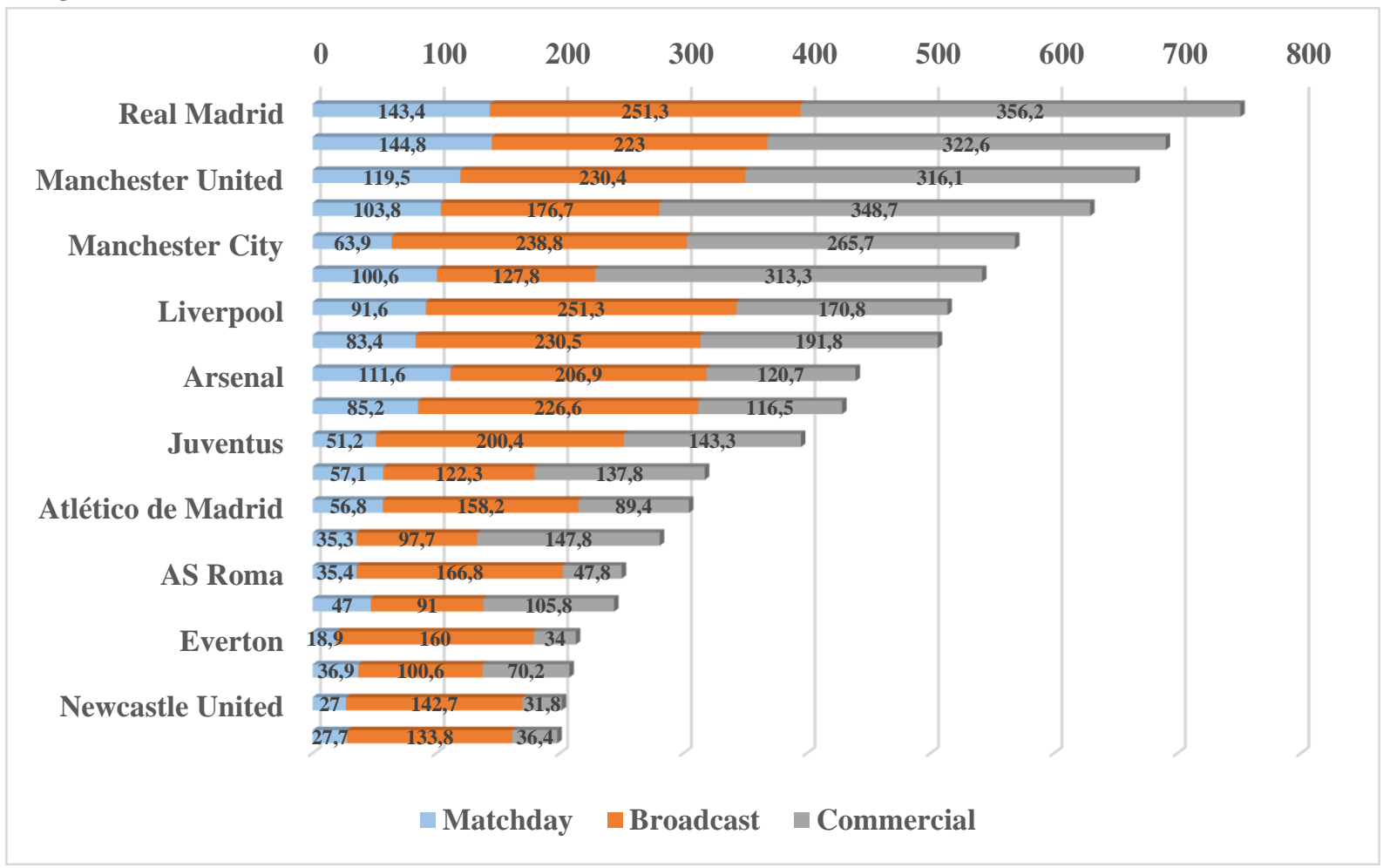

Fonte: Elaborados pelos autores.

Conforme explícito na metodologia, aplicou-se os indicadores de liquidez, endividamento e rentabilidade às demonstrações contábeis dos 20 clubes com maior faturamento mundial, obtendo os seguintes resultados: 
Braga, D. C., Paixão, C. V., Pereira, I. B., \& Santos, M. P. (2021, set./dez.). Fatores de competitividade que influenciam a escolha do turista entre o transporte aéreo e os trens de alta velocidade: uma revisão da literatura publicada em inglês $(\mathbf{1 9 9 5 - 2 0 2 0})$

\section{Tabela 4}

Resultado dos Indicadores Financeiros dos Anos 2017/2018

\begin{tabular}{lllllllll}
\hline & \multicolumn{3}{c}{ Liquidez } & \multicolumn{3}{c}{ Endividamento } & \multicolumn{3}{c}{ Rentabilidade } \\
& LI & LC & LG & PCT & CE & ML & ROI & ROE \\
\hline Real Madrid CF & 0,4126 & 0,7693 & 0,6582 & 0,5459 & 0,7751 & 0,0413 & 0,0285 & 0,0627 \\
\hline FC Barcelona & 0,0591 & 0,3455 & 0,4318 & 0,8738 & 0,7688 & 0,0188 & 0,0127 & 0,1009 \\
\hline Manchester United FC & 0,5210 & 0,8901 & 0,4348 & 0,7250 & 0,4143 & $-0,0632$ & $-0,0241$ & $-0,0876$ \\
\hline FC Bayern Munich & 1,4215 & 1,7686 & 1,4195 & 0,3094 & 0,7596 & 0,0455 & 0,0447 & 0,0647 \\
\hline Manchester City FC & 0,0800 & 0,7229 & 0,6061 & 0,3812 & 0,7576 & 0,0209 & 0,0087 & 0,0140 \\
\hline Paris Saint-Germain FC & 0,6781 & 1,8297 & 1,0724 & 0,4639 & 0,4318 & 0,0566 & 0,0310 & 0,0579 \\
\hline Liverpool FC & 0,0308 & 0,6159 & 0,4673 & 0,6875 & 0,7310 & 0,2329 & 0,1591 & 0,5091 \\
\hline Chelsea FC & 0,0998 & 0,4436 & 0,5502 & 0,4802 & 0,8748 & 0,1399 & 0,0821 & 0,1580 \\
\hline Arsenal FC & 0,9407 & 1,3524 & 0,5907 & 0,5919 & 0,4037 & 0,1392 & 0,0550 & 0,1347 \\
\hline Tottenham Hotspur FC & 0,3565 & 0,6010 & 0,1802 & 0,7421 & 0,2928 & 0,2967 & 0,0869 & 0,3370 \\
\hline Juventus FC & 0,0534 & 0,5284 & 0,3463 & 0,9004 & 0,4411 & $-0,0381$ & $-0,0266$ & $-0,2669$ \\
\hline Borussia Dortmund & 0,4996 & 1,1460 & 1,3207 & 0,2969 & 0,8381 & 0,0531 & 0,0595 & 0,0846 \\
\hline Club Atlético de Madrid & 0,0499 & 0,5914 & 0,3444 & 0,9044 & 0,5692 & 0,0135 & 0,0050 & 0,0525 \\
\hline FC Internazionale & 0,1072 & 0,7211 & 0,6474 & 0,9955 & 0,4967 & $-0,0616$ & $-0,0209$ & $-4,6331$ \\
\hline AS Roma & 0,1347 & 0,6060 & 0,3557 & N/A & 0,3940 & $-0,1022$ & $-0,0538$ & N/A \\
\hline Schalke 04 & 0,0297 & 0,2263 & 0,2168 & 0,9699 & 0,8919 & 0,1155 & 0,1595 & 5,2945 \\
\hline Everton FC & 0,0469 & 0,4040 & 0,4896 & 0,6776 & 0,7794 & $-0,0692$ & $-0,0342$ & $-0,1062$ \\
\hline AC Milan & 0,0528 & 0,2092 & 0,2164 & 0,9741 & 0,7900 & $-0,5739$ & $-0,2460$ & $-9,5145$ \\
\hline Newcastle United FC & 0,3347 & 0,7911 & 0,4127 & 0,9683 & 0,4013 & 0,1042 & 0,0715 & 2,2522 \\
\hline West Ham United FC & 0,3102 & 0,5544 & 0,4805 & 0,9576 & 0,5581 & 0,0991 & 0,0943 & 2,2241 \\
\hline MÉDIA & 0,3110 & 0,7558 & 0,5621 & 0,7077 & 0,6185 & 0,0234 & 0,0246 & $-0,1717$ \\
\hline MEDIANA & 0,1210 & 0,6110 & 0,4739 & 0,7250 & 0,6501 & 0,0434 & 0,0297 & 0,0647 \\
\hline
\end{tabular}

Fonte: Elaborados pelos autores.

Com relação aos indicadores de liquidez, observa-se que apenas a equipe do Bayern de Munich possui recursos suficientes para cumprir com suas obrigações de curtíssimo prazo, isto é, de forma imediata. Em curto prazo, que considera as obrigações vencíveis dentro do período de um ano, Bayern de Munich, Paris Saint-Germain, Arsenal e Borussia Dortmund são as equipes que possuem bens e direitos capazes de quitar suas obrigações. Em contrapartida, considerando todas as obrigações, observa-se que das 20 equipes estudadas, apenas 3 possuem capacidade para quitar seus compromissos com os credores, sendo elas: Bayern de Munich, Paris Saint Germain e Borussia Dortmund. É possível destacar ainda que, em média, as equipes 
Mendes, R. C., \& Gonçalves, R. S. Terceiro tempo: análise do desempenho financeiro dos maiores clubes desportivos mundiais e aplicação das técnicas de índice padrão e modelo de solvência

possuem $31 \%$ do ativo necessário para quitar com seu passivo em curtíssimo prazo, $75 \%$ a curto prazo e $56 \%$ a longo prazo, o que evidencia que grande parte de suas receitas não tem transformado-se em bens e direitos.

No que refere-se aos indicadores de endividamento, o estudo demonstra que, grande parte dos clubes, financiam suas atividades majoritariamente com capital de terceiros. Apenas Bayern de Munich, Manchester City, Paris Saint-Germain, Chelsea e Borussia Dortmund possuem em sua estrutura de capital, maior porcentagem de capital próprio em relação ao capital de terceiros, que tende a ser um capital oneroso, que incorre despesas financeiras e prazo de vencimento. Em média, os clubes financiam-se em 70,77\% com capital de terceiros e, apenas, 29,23\% com capital próprio. Destaca-se ainda que não foi possível aplicar o indicador nas demonstrações da Roma, visto que a mesma possui um patrimônio líquido negativo, o que evidencia um passivo a descoberto.

Ainda sobre os indicadores de endividamento, a composição do endividamento revelou outro fator preocupante. Apenas a equipe do Tottenham Hotspur tem suas dívidas de curto prazo abaixo de $30 \%$ em relação às suas obrigações totais. Isto revela que, grande parte das obrigações dos clubes, são vencíveis em até 360 dias, revelando a necessidade de geração de caixa em curto prazo.

Em sequência, os indicadores de rentabilidade possuem grande importância na análise econômico-financeira dos clubes, pois evidencia quanto os clubes transformaram em lucro de seu total de receita captada, do total investido em seu ativo, e do total de seu capital próprio. Os resultados mostraram que, apesar de os clubes captarem grande montante de receitas e estarem entre as 20 equipes com maior faturamento mundial, uma pequena parte dessa receita transformou-se em lucro no fim da apuração contábil. Em média, apenas 2,34\% do total captado configurou-se como lucro. Além disso, as equipes do Manchester United, Juventus, Internazionale, Roma, Everton e Milan consumiram todas suas receitas e ainda apuraram prejuízo.

Dando prosseguimento, a tabela abaixo demonstra o índice padrão para o setor, determinados por decis, calculados com base nos resultados dos indicadores. 
Braga, D. C., Paixão, C. V., Pereira, I. B., \& Santos, M. P. (2021, set./dez.). Fatores de competitividade que influenciam a escolha do turista entre o transporte aéreo e os trens de alta velocidade: uma revisão da literatura publicada em inglês (1995-2020)

\section{Tabela 5}

Índice Padrão dos Indicadores Para os Anos de 2017/2018

\begin{tabular}{cccccccccc}
\hline Índice & $\mathbf{1}^{\mathbf{0}}$ Decil & $\mathbf{2}^{\mathbf{0}}$ Decil & $\mathbf{3}^{\mathbf{0}}$ Decil & $\mathbf{4}^{\mathbf{0}}$ Decil & $\mathbf{5}^{\mathbf{}}$ Decil & $\mathbf{6}^{\mathbf{0}}$ Decil & $\mathbf{7}^{\mathbf{0}}$ Decil & $\begin{array}{c}\mathbf{8}^{\mathbf{0}} \\
\text { Decil }\end{array}$ & $\begin{array}{c}\mathbf{9}^{\mathbf{0}} \\
\text { Decil }\end{array}$ \\
\hline LI & 0,04 & 0,05 & 0,06 & 0,09 & 0,12 & 0,32 & 0,39 & 0,51 & 0,81 \\
$\mathbf{L C}$ & 0,29 & 0,42 & 0,54 & 0,60 & 0,61 & 0,72 & 0,78 & 1,02 & 1,56 \\
\hline LG & 0,22 & 0,35 & 0,38 & 0,43 & 0,47 & 0,52 & 0,60 & 0,65 & 1,20 \\
\hline PCT & 0,35 & 0,47 & 0,57 & 0,68 & 0,73 & 0,89 & 0,93 & 0,97 & 0,98 \\
CE & 0,40 & 0,41 & 0,44 & 0,53 & 0,65 & 0,76 & 0,77 & 0,78 & 0,86 \\
\hline ML & $-0,09$ & $-0,06$ & $-0,01$ & 0,02 & 0,04 & 0,05 & 0,10 & 0,13 & 0,19 \\
\hline ROI & $-0,04$ & $-0,03$ & $-0,01$ & 0,01 & 0,03 & 0,05 & 0,07 & 0,08 & 0,13 \\
\hline ROE & $-2,45$ & $-0,10$ & 0,03 & 0,06 & 0,07 & 0,12 & 0,25 & 1,37 & 3,77 \\
\hline
\end{tabular}

Fonte: Elaborados pelos autores.

Com base na tabela 5, os indicadores foram divididos em decis, de modo que permita que cada clube de futebol possa ser analisado de forma individual e enquadrado em uma das partes descritas acima. Ressalta-se que o $5^{\circ}$ decil representa a mediana e cada clube recebeu os conceitos de péssimo, muito ruim, ruim, razoável (mediana), bom, muito bom e ótimo expostos na metodologia, conforme seu desempenho em cada um dos indicadores calculados, representando sua atuação econômica e financeira para a temporada de 2017/2018. 
Mendes, R. C., \& Gonçalves, R. S. Terceiro tempo: análise do desempenho financeiro dos maiores clubes desportivos mundiais e aplicação das técnicas de índice padrão e modelo de solvência

\section{Tabela 6}

Conceito dos Indicadores Financeiros dos Anos 2017/2018

\begin{tabular}{|c|c|c|c|c|c|c|c|c|}
\hline & LI & LC & LG & PCT & $\mathrm{CE}$ & ML & ROI & ROE \\
\hline $\begin{array}{l}\text { Real Madrid } \\
\text { CF }\end{array}$ & Bom & Bom & $\begin{array}{l}\text { Muito } \\
\text { Bom }\end{array}$ & $\begin{array}{l}\text { Muito } \\
\text { Bom }\end{array}$ & $\begin{array}{l}\text { Muito } \\
\text { Ruim }\end{array}$ & Razoável & Razoável & Ruim \\
\hline FC Barcelona & Ruim & Péssimo & Ruim & Razoável & Ruim & Ruim & Ruim & Razoável \\
\hline $\begin{array}{l}\text { Manchester } \\
\text { United FC }\end{array}$ & $\begin{array}{l}\text { Muito } \\
\text { Bom }\end{array}$ & Bom & Ruim & Bom & $\begin{array}{l}\text { Muito } \\
\text { Bom }\end{array}$ & $\begin{array}{l}\text { Muito } \\
\text { Ruim }\end{array}$ & $\begin{array}{l}\text { Muito } \\
\text { Ruim }\end{array}$ & $\begin{array}{l}\text { Muito } \\
\text { Ruim }\end{array}$ \\
\hline $\begin{array}{l}\text { FC Bayern } \\
\text { Munich }\end{array}$ & Ótimo & Ótimo & Ótimo & Ótimo & Ruim & Bom & Razoável & Ruim \\
\hline $\begin{array}{l}\text { Manchester } \\
\text { City FC }\end{array}$ & Ruim & Bom & Bom & Ótimo & Ruim & Ruim & Ruim & $\begin{array}{l}\text { Muito } \\
\text { Ruim }\end{array}$ \\
\hline $\begin{array}{l}\text { Paris Saint- } \\
\text { Germain FC }\end{array}$ & $\begin{array}{l}\text { Muito } \\
\text { Bom }\end{array}$ & Ótimo & $\begin{array}{l}\text { Muito } \\
\text { Bom }\end{array}$ & Ótimo & $\begin{array}{l}\text { Muito } \\
\text { Bom }\end{array}$ & Bom & Razoável & Ruim \\
\hline Liverpool FC & Péssimo & Razoável & Razoável & Bom & Razoável & Ótimo & Ótimo & Bom \\
\hline Chelsea FC & Ruim & $\begin{array}{l}\text { Muito } \\
\text { Ruim }\end{array}$ & Bom & $\begin{array}{l}\text { Muito } \\
\text { Bom }\end{array}$ & Péssimo & $\begin{array}{l}\text { Muito } \\
\text { Bom }\end{array}$ & $\begin{array}{l}\text { Muito } \\
\text { Bom }\end{array}$ & Bom \\
\hline Arsenal FC & Ótimo & $\begin{array}{l}\text { Muito } \\
\text { Bom }\end{array}$ & Bom & Bom & Ótimo & $\begin{array}{l}\text { Muito } \\
\text { Bom }\end{array}$ & Bom & Bom \\
\hline $\begin{array}{l}\text { Tottenham } \\
\text { Hotspur FC }\end{array}$ & Bom & Ruim & Péssimo & Razoável & Ótimo & Ótimo & $\begin{array}{l}\text { Muito } \\
\text { Bom }\end{array}$ & Bom \\
\hline Juventus FC & $\begin{array}{l}\text { Muito } \\
\text { Ruim }\end{array}$ & $\begin{array}{l}\text { Muito } \\
\text { Ruim }\end{array}$ & $\begin{array}{l}\text { Muito } \\
\text { Ruim }\end{array}$ & Ruim & Bom & Péssimo & $\begin{array}{l}\text { Muito } \\
\text { Ruim }\end{array}$ & Péssimo \\
\hline $\begin{array}{l}\text { Borussia } \\
\text { Dortmund }\end{array}$ & Bom & $\begin{array}{l}\text { Muito } \\
\text { Bom }\end{array}$ & Ótimo & Ótimo & $\begin{array}{l}\text { Muito } \\
\text { Ruim }\end{array}$ & Bom & Bom & Razoável \\
\hline $\begin{array}{l}\text { Club Atlético } \\
\text { de Madrid }\end{array}$ & $\begin{array}{l}\text { Muito } \\
\text { Ruim }\end{array}$ & Ruim & Péssimo & Ruim & Bom & Ruim & Ruim & Ruim \\
\hline $\begin{array}{l}\text { FC } \\
\text { Internazionale }\end{array}$ & Ruim & Bom & $\begin{array}{l}\text { Muito } \\
\text { Bom }\end{array}$ & Péssimo & Bom & $\begin{array}{l}\text { Muito } \\
\text { Ruim }\end{array}$ & $\begin{array}{l}\text { Muito } \\
\text { Ruim }\end{array}$ & Péssimo \\
\hline AS Roma & Razoável & Razoável & $\begin{array}{l}\text { Muito } \\
\text { Ruim }\end{array}$ & Péssimo & Ótimo & Péssimo & Péssimo & Péssimo \\
\hline Schalke 04 & Péssimo & Péssimo & $\begin{array}{l}\text { Muito } \\
\text { Ruim }\end{array}$ & $\begin{array}{l}\text { Muito } \\
\text { Ruim }\end{array}$ & Péssimo & Bom & Ótimo & Ótimo \\
\hline Everton FC & $\begin{array}{l}\text { Muito } \\
\text { Ruim }\end{array}$ & Péssimo & Razoável & Bom & $\begin{array}{l}\text { Muito } \\
\text { Ruim }\end{array}$ & Péssimo & $\begin{array}{l}\text { Muito } \\
\text { Ruim }\end{array}$ & Péssimo \\
\hline AC Milan & $\begin{array}{l}\text { Muito } \\
\text { Ruim }\end{array}$ & Péssimo & Péssimo & $\begin{array}{l}\text { Muito } \\
\text { Ruim }\end{array}$ & $\begin{array}{l}\text { Muito } \\
\text { Ruim }\end{array}$ & Péssimo & Péssimo & Péssimo \\
\hline $\begin{array}{l}\text { Newcastle } \\
\text { United FC }\end{array}$ & Bom & Bom & Ruim & $\begin{array}{l}\text { Muito } \\
\text { Ruim }\end{array}$ & Ótimo & Bom & Bom & $\begin{array}{l}\text { Muito } \\
\text { Bom }\end{array}$ \\
\hline $\begin{array}{l}\text { West Ham } \\
\text { United FC }\end{array}$ & Razoável & Ruim & Razoável & Ruim & Bom & Bom & $\begin{array}{l}\text { Muito } \\
\text { Bom }\end{array}$ & $\begin{array}{l}\text { Muito } \\
\text { Bom }\end{array}$ \\
\hline
\end{tabular}

Fonte: Elaborados pelos autores.

Para uma eficiente interpretação da análise econômico-financeira dos clubes cabe não só calculá-los individualmente, como também compará-los com uma amostragem de seu respectivo setor. Isto deve-se ao fato de que um indicador, quando analisado isoladamente, pode ser considerado satisfatório e, ao ser comparado com o índice-padrão, apresentar uma interpretação diferente. 
Braga, D. C., Paixão, C. V., Pereira, I. B., \& Santos, M. P. (2021, set./dez.). Fatores de competitividade que influenciam a escolha do turista entre o transporte aéreo e os trens de alta velocidade: uma revisão da literatura publicada em inglês (1995-2020)

Com este objetivo, a tabela 7 evidenciou os conceitos dos indicadores de todas as 20 equipes aqui estudadas em comparação com o índice-padrão setorial. Percebe-se que todas as equipes tiveram bastante variações nos conceitos obtidos, não havendo um mesmo padrão de conceitos no tripé liquidez, endividamento e rentabilidade.

Para melhor analisar o padrão das equipes estudadas, analisa-se, a seguir, a frequência dos conceitos e sua porcentagem de participação nos indicadores estudados, revelando o padrão de comportamento do indicador nos clubes alvo do estudo.

\section{Tabela 7}

Frequência dos Conceitos Para os Indicadores Calculados

\begin{tabular}{llllllll}
\hline \multicolumn{1}{c}{ Índice } & Péssimo & $\begin{array}{c}\text { Muito } \\
\text { Ruim }\end{array}$ & Ruim & Razoável & Bom & $\begin{array}{c}\text { Muito } \\
\text { Bom }\end{array}$ & Ótimo \\
\hline LI & $10 \%$ & $20 \%$ & $20 \%$ & $10 \%$ & $20 \%$ & $10 \%$ & $10 \%$ \\
LC & $20 \%$ & $10 \%$ & $15 \%$ & $10 \%$ & $25 \%$ & $10 \%$ & $10 \%$ \\
\hline LG & $15 \%$ & $15 \%$ & $15 \%$ & $15 \%$ & $15 \%$ & $15 \%$ & $10 \%$ \\
\hline PCT & $10 \%$ & $15 \%$ & $15 \%$ & $10 \%$ & $20 \%$ & $10 \%$ & $20 \%$ \\
CE & $10 \%$ & $20 \%$ & $15 \%$ & $5 \%$ & $20 \%$ & $10 \%$ & $20 \%$ \\
ML & $20 \%$ & $10 \%$ & $15 \%$ & $5 \%$ & $30 \%$ & $10 \%$ & $10 \%$ \\
\hline ROI & $10 \%$ & $20 \%$ & $15 \%$ & $15 \%$ & $15 \%$ & $15 \%$ & $10 \%$ \\
\hline ROE & $25 \%$ & $10 \%$ & $20 \%$ & $10 \%$ & $20 \%$ & $10 \%$ & $5 \%$ \\
\hline MÉDIA & $15 \%$ & $15 \%$ & $16 \%$ & $10 \%$ & $21 \%$ & $11 \%$ & $12 \%$ \\
MEDIANA & $12,5 \%$ & $15 \%$ & $15 \%$ & $10 \%$ & $20 \%$ & $10 \%$ & $10 \%$ \\
\hline
\end{tabular}

Fonte: Elaborados pelos autores.

Como os resultados dos indicadores das equipes foram bastante variados, tal comportamento refletiu, de forma lógica, na frequência dos conceitos em cada um dos índices financeiros. No entanto, cabe ressaltar que, na média, assim como na mediana, o conceito "bom" obteve maior frequência de aparição.

De acordo com a metodologia proposta, é possível perceber, na tabela adaptada de Matarazzo (1998), que os conceitos obtidos pelos clubes são acompanhados por pontos, possibilitando a criação de um ranking econômico-financeiro dos 20 clubes de futebol com maior faturamento mundial. 
Mendes, R. C., \& Gonçalves, R. S. Terceiro tempo: análise do desempenho financeiro dos maiores clubes desportivos mundiais e aplicação das técnicas de índice padrão e modelo de solvência

Tabela 8

Pontos Obtidos Pelas Equipes nos Indicadores

\begin{tabular}{lccccccccc}
\hline & LI & LC & LG & PCT & CE & ML & ROI & ROE & TOTAL \\
\hline Arsenal FC & 9 & 8 & 6 & 7 & 9 & 8 & 6 & 6 & $\mathbf{5 9}$ \\
Paris Saint-Germain FC & 8 & 9 & 8 & 9 & 8 & 6 & 5 & 4 & $\mathbf{5 7}$ \\
FC Bayern Munich & 9 & 9 & 9 & 9 & 4 & 6 & 5 & 4 & $\mathbf{5 5}$ \\
Borussia Dortmund & 7 & 8 & 9 & 9 & 2 & 6 & 4 & 5 & $\mathbf{5 0}$ \\
Newcastle United FC & 6 & 7 & 3 & 2 & 9 & 7 & 7 & 8 & $\mathbf{4 9}$ \\
Tottenham Hotspur FC & 6 & 4 & 0 & 5 & 9 & 9 & 8 & 7 & $\mathbf{4 8}$ \\
Liverpool FC & 0 & 5 & 5 & 6 & 5 & 9 & 9 & 7 & $\mathbf{4 6}$ \\
Real Madrid CF & 7 & 6 & 8 & 8 & 2 & 5 & 5 & 4 & $\mathbf{4 5}$ \\
Manchester United FC & 8 & 7 & 4 & 6 & 8 & 8 & 2 & 2 & $\mathbf{4 5}$ \\
Chelsea FC & 4 & 2 & 6 & 8 & 0 & 8 & 8 & 6 & $\mathbf{4 2}$ \\
West Ham United FC & 5 & 3 & 5 & 3 & 6 & 4 & 8 & 8 & $\mathbf{4 2}$ \\
Manchester City FC & 3 & 6 & 7 & 9 & 4 & 4 & 4 & 2 & $\mathbf{3 9}$ \\
Schalke 04 & 0 & 0 & 2 & 2 & 1 & 7 & 9 & 9 & $\mathbf{3 0}$ \\
FC Barcelona & 3 & 1 & 4 & 5 & 3 & 4 & 4 & 5 & $\mathbf{2 9}$ \\
Club Atlético de Madrid & 2 & 3 & 1 & 4 & 7 & 3 & 4 & 3 & $\mathbf{2 7}$ \\
FC Internazionale & 4 & 6 & 3 & 1 & 7 & 2 & 2 & 0 & $\mathbf{2 5}$ \\
AS Roma & 5 & 5 & 2 & 0 & 9 & 2 & 2 & 0 & $\mathbf{2 5}$ \\
Juventus FC & 2 & 2 & 2 & 4 & 7 & 2 & 2 & 1 & $\mathbf{2 2}$ \\
Everton FC & 2 & 1 & 5 & 6 & 2 & 1 & 2 & 1 & $\mathbf{2 0}$ \\
AC Milan & 2 & 0 & 1 & 2 & 2 & 0 & 0 & 0 & $\mathbf{7}$ \\
\hline
\end{tabular}

Fonte: Elaborados pelos autores.

Para efeito de comparação, a tabela abaixo demonstra a posição dos clubes no ranking econômico-financeiro em comparação com a posição dos mesmos no ranking publicado pela União das Associações Europeias de Futebol - UEFA, para a temporada 2017/2018, filtrando apenas as 20 equipes selecionadas para este estudo. 
Braga, D. C., Paixão, C. V., Pereira, I. B., \& Santos, M. P. (2021, set./dez.). Fatores de competitividade que influenciam a escolha do turista entre o transporte aéreo e os trens de alta velocidade: uma revisão da literatura publicada em inglês (1995-2020)

\section{Tabela 9}

Ranking Financeiro x Ranking Desportivo

\begin{tabular}{lll}
\hline & \multicolumn{1}{c}{$\begin{array}{c}\text { Posição } \\
\text { Financeira }\end{array}$} & $\begin{array}{c}\text { Posição } \\
\text { Desportiva }\end{array}$ \\
\hline Arsenal FC & 1 & 8 \\
Paris Saint-Germain FC & 2 & 6 \\
FC Bayern Munich & 3 & 3 \\
Borussia Dortmund & 4 & 9 \\
Newcastle United FC & 5 & 20 \\
Tottenham Hotspur FC & 6 & 12 \\
Liverpool FC & 7 & 14 \\
Real Madrid CF & 8 & 1 \\
Manchester United FC & 9 & 10 \\
Chelsea FC & 10 & 11 \\
West Ham United FC & 11 & 19 \\
Manchester City FC & 12 & 7 \\
Schalke 04 & 13 & 15 \\
FC Barcelona & 14 & 4 \\
Club Atlético de Madrid & 15 & 2 \\
FC Internazionale & 16 & 18 \\
AS Roma & 17 & 13 \\
Juventus FC & 18 & 5 \\
Everton FC & 19 & 17 \\
AC Milan & 20 & 16 \\
\hline
\end{tabular}

Fonte: Elaborados pelos autores.

A tabela revela que somente a equipe do Bayern Munich manteve a mesma posição em ambos os rankings. Todas as demais equipes obtiveram diferenças consideráveis entre seu desempenho econômico-financeiro e esportivo.

Por exemplo, a equipe do Atlético de Madrid foi considerada pela UEFA a $2^{\text {a }}$ equipe com melhor desempenho esportivo na temporada de 2017/2018, enquanto financeiramente ocupou a $15^{\text {a }}$ posição. Em sentido contrário, a equipe do Newcastle United obteve o $5^{\circ}$ melhor desempenho financeiro, mas, em contrapartida, foi a pior equipe desportiva entre as estudadas.

Por fim, aplicou-se três modelos de solvência propostos por estudiosos da temática às demonstrações dos clubes, conforme demonstra-se abaixo. 
Mendes, R. C., \& Gonçalves, R. S. Terceiro tempo: análise do desempenho financeiro dos maiores clubes desportivos mundiais e aplicação das técnicas de índice padrão e modelo de solvência

\section{Tabela 10}

Análise de Solvência dos Clubes

\begin{tabular}{|c|c|c|c|c|c|c|}
\hline & $\begin{array}{l}\text { Modelo } \\
\text { Altman }\end{array}$ & $\begin{array}{c}\text { Modelo } \\
\text { Elizabetsky }\end{array}$ & $\begin{array}{c}\text { Modelo } \\
\text { Kanitz }\end{array}$ & $\begin{array}{c}\text { Resultado } \\
\text { Altman }\end{array}$ & $\begin{array}{c}\text { Resultado } \\
\text { Elizabetsky }\end{array}$ & $\begin{array}{c}\text { Resultado } \\
\text { Kanitz }\end{array}$ \\
\hline Arsenal FC & $-0,6991$ & 0,0671 & 3,6290 & Insolvente & Insolvente & Solvente \\
\hline Paris Saint-Germain FC & $-0,5673$ & $-0,0357$ & 6,0427 & Insolvente & Insolvente & Solvente \\
\hline FC Bayern Munich & 0,5276 & $-0,1679$ & 6,3526 & Solvente & Insolvente & Solvente \\
\hline Borussia Dortmund & 0,8932 & $-0,0834$ & 4,8962 & Solvente & Insolvente & Solvente \\
\hline Newcastle United FC & $-0,8977$ & $-0,0024$ & $-7,3020$ & Insolvente & Insolvente & Insolvente \\
\hline Tottenham Hotspur FC & $-0,6297$ & 0,3669 & 0,7939 & Insolvente & Insolvente & Solvente \\
\hline Liverpool FC & 0,1302 & 0,1981 & 1,5100 & Solvente & Insolvente & Solvente \\
\hline Real Madrid CF & $-0,5742$ & $-0,2802$ & 2,5796 & Insolvente & Insolvente & Solvente \\
\hline Manchester United FC & $-1,1712$ & $-0,3889$ & 2,0486 & Insolvente & Insolvente & Solvente \\
\hline Chelsea FC & $-0,0767$ & 0,0148 & 1,7145 & Insolvente & Insolvente & Solvente \\
\hline West Ham United FC & $-0,4279$ & $-0,1647$ & $-5,2485$ & Insolvente & Insolvente & Insolvente \\
\hline Manchester City FC & $-0,3382$ & $-0,0535$ & 2,5975 & Insolvente & Insolvente & Solvente \\
\hline Schalke 04 & 0,5136 & $-0,5232$ & $-9,4768$ & Solvente & Insolvente & Insolvente \\
\hline FC Barcelona & $-0,9563$ & $-0,4330$ & $-0,7080$ & Insolvente & Insolvente & Indefinida \\
\hline Club Atlético de Madrid & $-1,1999$ & $-0,4840$ & $-1,0918$ & Insolvente & Insolvente & Indefinida \\
\hline FC Internazionale & $-1,4022$ & $-0,4647$ & $-70,2877$ & Insolvente & Insolvente & Insolvente \\
\hline AS Roma & $-1,5006$ & $-0,4944$ & 3,9128 & Insolvente & Insolvente & Solvente \\
\hline Juventus FC & $-1,3376$ & $-0,2888$ & $-1,1780$ & Insolvente & Insolvente & Indefinida \\
\hline Everton FC & $-1,2485$ & $-0,4194$ & 1,1151 & Insolvente & Insolvente & Solvente \\
\hline AC Milan & $-2,4770$ & $-1,7484$ & $-12,0324$ & Insolvente & Insolvente & Insolvente \\
\hline
\end{tabular}

Fonte: Elaborados pelos autores.

Os resultados mostraram-se pouco explicativos, visto que não foi possível observar um padrão para grande parte das equipes pesquisadas. Essa limitação pode ser explicada devido ao fato de os modelos propostos conterem contas não relevantes para o setor dos clubes desportivos, como por exemplo, os estoques.

\section{Considerações finais}

Esta pesquisa objetivou analisar o desempenho econômico-financeiro dos clubes de futebol com as vinte maiores receitas do mundo, segundo o estudo da Delloite Football Money League e aplicar as técnicas de análise das demonstrações contábeis de índice padrão e modelo de solvência. 
Braga, D. C., Paixão, C. V., Pereira, I. B., \& Santos, M. P. (2021, set./dez.). Fatores de competitividade que influenciam a escolha do turista entre o transporte aéreo e os trens de alta velocidade: uma revisão da literatura publicada em inglês $(\mathbf{1 9 9 5 - 2 0 2 0})$

Com base nos resultados, foi possível perceber que os clubes, em geral, apresentam níveis de liquidez abaixo do recomendado pela literatura quando analisados de forma individual. Em média, os clubes não possuem capacidade de arcar com suas obrigações, principalmente aquelas de prazo imediato. A liquidez de curto prazo é a mais favorável, onde os clubes, em média, possuem capacidade de cumprir com $75 \%$ de suas obrigações. Uma possível explicação para a baixa liquidez ocorre no sentido de que as entidades desportivas possuem altos valores nas contas de intangíveis e imobilizado, sendo representado, respectivamente, por gastos na aquisição de atletas e em seus respectivos estádios e centros de treinamentos. Assim, os clubes concentram sua aplicação de recursos no ativo não circulante e, consequentemente, com valores menores no ativo de curto prazo.

Quanto aos indicadores de endividamento, percebe-se que de forma geral, os clubes financiam suas atividades majoritariamente com capital de terceiros, que representa um capital oneroso e com prazo de vencimento. Outro fator preocupante quanto ao endividamento evidenciou que, das 20 equipes estudadas, 19 possuem uma proporção de dívidas maior a curto prazo, isto é, vencíveis em até 360 dias, gerando assim uma necessidade grande de caixa para os próximos meses.

Devido às especificidades presentes neste mercado, grande parte dos clubes não possuem mecanismos para realizar captação via recursos próprios, fazendo com que a captação via capital de terceiros seja amplamente explorada. Outro fator importante que tende a contribuir com este fato consiste na extinção das reservas de reavaliação com as normas internacionais, fazendo com que os valores do imobilizado não sofram aumento com a valorização e, por conseguinte, resultem em uma conta de patrimônio líquido constante.

Não distante dos resultados acima encontram-se os indicadores de rentabilidade. A interpretação revelou que, apesar de os clubes representarem os 20 clubes desportivos com maior captação de receita, uma pequena parte desta transformou-se em lucro ao fim da apuração contábil. Em média, apenas 2,34\% do total captado transformou-se em lucro, revelando que os clubes possuem grande estrutura de custos e despesas, sendo justificado pela característica do mercado futebolístico em possuir salários elevados no seu departamento de futebol.

Por fim, a análise de solvência demonstrou que os modelos propostos possuem baixa explicação para o setor de clubes desportivos, visto que seus resultados foram pouco unânimes, evidenciando que as contas propostas no modelo possuem baixo nível de explicação para o setor estudado. Para estudos futuros, propõe-se a utilização da metodologia empregada nos 
Mendes, R. C., \& Gonçalves, R. S. Terceiro tempo: análise do desempenho financeiro dos maiores clubes desportivos mundiais e aplicação das técnicas de índice padrão e modelo de solvência

clássicos modelos de solvência em indicadores que expliquem, com maior nível informacional, o desempenho econômico-financeiro de clubes desportivos.

\section{Referências}

Altman, E. (1968). Financial ratios, Discriminant analysis and the prediction of corporate bankruptcy. Journal of Finance, 23(4), 589-609. https://doi.org/10.2307/2978933

Barros, C. P., Assaf, A., \& Sá, F. E. (2010). Brazilian football league technical efficiency: a Simar and Wilson approach. Journal of Sports Economics, 11(6), 641-651. https://doi.org/10.1177/1527002509357530

Deloitte Sports Business Group. (2019). Deloitte Football Money League 2019. Disponível em https://www2.deloitte.com/br/pt/pages/consumer-business/articles/Deloitte-FootballMoney-League.html Acesso em 19 de junho de 2019.

Dos Santos, R. I., Da Silva, V., Da Costa, C. E. S., \& Cavalcante, P. S. (2020). Desempenhos Econômico e Financeiro dos Clubes de Futebol Participantes dos Campeonatos Brasileiros das Séries A, B e C no Ano de 2017. CAFI-Contabilidade, Atuária, Finanças \& Informação, 3(1), 67-82. https://doi.org/10.23925/cafi.v3i1.45039

Duarte, H. C. F., \& Lamounier, W. M. (2007). Análise financeira de empresas da construção civil por comparação com índices-padrão. Enfoque: Reflexão Contábil, 26(2), 09-28. https://doi.org/10.4025/enfoque.v26i2.4786

Elizabetsky, R. (1976). Um modelo matemático para decisões de crédito no banco comercial. 190 p. Dissertação (Mestrado) - Escola Politécnica da Universidade de São Paulo, São Paulo - SP.

Fanti, L. D., Hrenechen, J. E., Miranda, J. M., da Silva, R. N., Reis, R. A. D., Dias, T. D. S., \& Lucena, L. P. D. (2016). Análise dos Principais Indicadores Contábeis e Financeiros: Um Estudo de Caso Sobre a VALE S/A nos Anos de 2011 e 2012. Desafio Online, 4(1), 100116.

Ferreira, H. L., Marques, J. A. V. C., \& Macedo, M. A. S. (2018). Desempenho econômicofinanceiro e desempenho esportivo: uma análise com clubes de futebol do Brasil. Contextus: Revista Contemporânea de economia e gestão, 16(3), 124-150. https://doi.org/10.19094/contextus.v16i3.39907

Gil, A. C. (2008). Métodos e Técnicas de Pesquisa Social. $6^{\mathrm{a}}$ ed. São Paulo: Atlas.

Gonçalves, R. S., Mendes, R. C., Henriques, F. M., \& Tavares, G. M. (2020). A influência do rendimento esportivo no desempenho econômico-financeiro: Uma análise com clubes de futebol brasileiros durante 2013-2017. Contextus - Revista Contemporânea De Economia E Gestão, 18, 239-250. https://doi.org/10.19094/contextus.2020.44392 
Braga, D. C., Paixão, C. V., Pereira, I. B., \& Santos, M. P. (2021, set./dez.). Fatores de competitividade que influenciam a escolha do turista entre o transporte aéreo e os trens de alta velocidade: uma revisão da literatura publicada em inglês $(\mathbf{1 9 9 5 - 2 0 2 0})$

Holanda, A. P., Meneses, A. F. D., Mapurunga, P. V. R., De Luca, M. M. M., \& Coelho, A. C. D. (2012). Determinantes do nível de disclosure em clubes brasileiros de futebol. Revista de Contabilidade do Mestrado em Ciências Contábeis da UERJ, 17(1), 2-17.

Kanitz, S. C. (1978). Como Prever Falências. São Paulo: McGraw-Hill.

Kauark, F. S.; Manhães, F. C.; Medeiros, C. H. (2010). Metodologia de Pesquisa: um guia prático. Itabuna, BA: Via Litterarum.

Lemos, L. F. B., \& Soares, R. O. (2012). Previsão de insolvência em micro e pequenas empresas utilizando indicadores contábeis. Revista de Empreendedorismo e Gestão de Pequenas Empresas, 1(3), 104-134. https://doi.org/10.14211/regepe.v1i3.40

Marion, J. C. (2009). Análise das Demonstrações Contábeis. São Paulo: Atlas.

Marques, D. S. P. (2014). Administração de clubes de futebol profissional: proposta de um modelo específico de governança para o setor. Tese (Doutorado) - Universidade de São Paulo, Ribeirão Preto - SP.

Matarazo, D. C. (2010). Análise Financeira de Balanços: abordagem gerencial. São Paulo: Atlas.

Padoveze, C. L., \& Benedicto, G. C. (2014). Análise das Demonstrações Financeiras. $3^{\mathrm{a}}$ ed. São Paulo: Cengage Learning.

Sakinc, I., Acikalin, S., \& Soyguden, A. (2017). Evaluation of the Relationship between financial Performance and Sport Success in European Football. Journal of Physical Education and Sport, 17, 16. https://doi.org/10.1108/MF-09-2020-0478

Silva, J. P. D. (2017). Análise Financeira das Empresas. 13ª ed. São Paulo: Cengage Learning.

Silva, L. R., Mello, J. A. V. B., Gonza, N. C., \& Orrico Filho, R. D. (2015). Índice padrão e análise da performance financeira das empresas concessionárias de exploração de Rodovias. Revista Scentia Plena, 11(3), 1-16.

Soares, M. L. (2007). A miopia do marketing esportivo dos clubes de futebol no Brasil: proposta de um modelo de gestão de marketing esportivo para os clubes brasileiros. $338 \mathrm{p}$. Tese (Doutorado) - Universidade de São Paulo, São Paulo - SP.

Tachizawa, T.; Ferreira, V. C. P.; \& Fortuna, A. A. M. (2004). Gestão com pessoas: uma abordagem aplicada às estratégias de negócios. Rio de Janeiro: Editora FGV.

Vargas, A. L. (1995). Desporto, fenômeno social. Rio de Janeiro: Sprint. 